\title{
A Ciência em reposta à pandemia de COVID-19: contribuições da Revista Brasileira de Atividade Física \& Saúde
}

\author{
Science as the answer for the COVID-19 pandemic: the contributions of the \\ Brazilian Journal of Physical Activity \& Health
}

\section{AUTORES \\ Pedro Curi Halla1 ${ }^{1,2}$ (D) \\ Valter Cordeiro Barbosa Filho ${ }^{3,4}$ (D) \\ Jeffer Eidi Sasaki ${ }^{5}$ (D) \\ 1 Universidade Federal de Pelotas, Programa de Pós-Graduação em Epidemiologia, Pelotas, Rio Grande do Sul, Brasil. \\ 2 Universidade Federal de Pelotas, Programa de Pós-Graduação em Educação Física, Pelotas, Rio Grande do Sul, Brasil. \\ 3 Instituto de Educação, Ciência e Tecnologia do Ceará - Campus Aracati, Aracati, Ceará, Brasil. \\ 4 Programa de Pós-Graduação em Saúde Coletiva, Universidade Estadual do Ceará, Fortaleza, Ceará, Brasil. \\ 5 Universidade Federal do Triângulo Mineiro Programa de Pós-Graduação em Educação Física, Uberaba, Minas Gerais, Brasil.}

\section{CONTATO}

Pedro Curi Hallal

prchallal@gmail.com

Universidade Federal de Pelotas, Programa de Pós-graduação em Epidemiologia.

Rua Marechal Deodoro 1160 - III piso, Centro, Pelotas, Rio Grande do Sul, Brasil. CEP: 96020-220.

DOI

$10.12820 /$ rbafs. $25 \mathrm{e} 0138$

\section{(cc) BY}

Este trabalho está licenciado com uma Licença Creative Commons - Atribuição 4.0 Internacional.
Num momento em que todas as atenções estão voltadas para o enfrentamento da pandemia de COVID-19, a ciência e a tecnologia ganham espaço na mídia, nas redes sociais e nas rodas de conversa. Discussões acaloradas sobre a necessidade de imunizar a população contra a COVID-19 chegam a incluir debate sobre as fases de desenvolvimento das vacinas. Os tratamentos medicamentosos para a COVID-19 são tratados como uma pauta de fé, dividindo a população entre aqueles que "creem" num medicamento e aqueles que não "creem". A divulgação de dados epidemiológicos concluiu que o Brasil é tanto o pior quanto o melhor país do mundo no enfrentamento da pandemia, dependendo de quem interpreta os dados. Pesquisadores são convidados a participarem de programas de televisão, de rádio, e suas opiniões são apresentadas nos principais jornais do país. É a glória (desculpem o trocadilho) da ciência brasileira \#SQN.

A verdade é que os investimentos em ciência e tecnologia diminuem a cada ano no Brasil. As universidades públicas, que respondem por mais de $90 \%$ da produção científica brasileira, são classificadas como o lugar da balbúrdia. O cenário é tão preocupante que dizer que a terra é plana parece natural. É nesse contexto que devemos interpretar o papel da ciência e da tecnologia no enfrentamento da pandemia. E ao olharmos desse lugar de fala, podemos afirmar que a ciência brasileira sai gigante dessa pandemia. Com todas as dificuldades, praticamente todas as áreas do conhecimento tem produzido ciência relevante para o enfrentamento da pandemia. E a atividade física e saúde não poderia ficar de fora.

Neste cenário, a Revista Brasileira de Atividade Física \& Saúde convidou, em 04 de abril de 2020, a comunidade científica para produzir e divulgar reflexões teóricas, resultados de pesquisa e de intervenção em atividade física e saúde que fossem relacionadas à pandemia de COVID-19.

A comunidade científica brasileira atendeu a chamada em altíssimo nível. Em menos de quatro meses, dezenas de trabalhos acadêmicos foram submetidos à Revista Brasileira de Atividade Física \& Saúde. Destes, 30 trabalhos foram aprovados e publicados, entre ensaios teóricos, pesquisas documentais/revisão, estudos originais transversais e de intervenção, os quais fomentaram discussões e propostas de intervenção relevantes para o desafiador cenário no qual ainda estamos. Três pontos podem ser destacados sobre os trabalhos publicados. Primeiro, o editorial escrito pelos professores James F. Sallis e Michael Pratt, o qual aborda os múltiplos benefícios 
da atividade física durante a pandemia de COVID-19. Segundo, os diferentes trabalhos sobre propostas de atividades físicas e/ou exercícios físicos para diferentes populações, incluindo pessoas com deficiência, idosos, crianças e adolescentes, usuários dos programas do Sistema Único de Saúde, entre outros. Terceiro, os ensaios e estudos originais nos ajudam a refletir sobre como as pesquisas da área de atividade física e saúde colaboram e auxiliam nas respostas para o enfrentamento da pandemia de COVID-19, com reverberações em saúde, inclusive, do ponto de vista econômico, social e político. Contribuições de pesquisadores de todo o Brasil de uma das áreas que teve importantes avanços ao longo dos anos no país.

Convidamos a todos a acessar, ler e divulgar os trabalhos do vigésimo quinto volume da Revista Brasileira de Atividade Física \& Saúde. Este periódico científico continua à disposição da comunidade científica e da população para contribuir com conhecimentos na área de atividade física e saúde, relacionados à pandemia da COVID-19 ou outros temas dentro do escopo. É o nosso papel enquanto periódico e sociedade científicos. É parte das contribuições que os diferentes pesquisadores, professores e cidadãos trouxeram à Sociedade e à Ciência.
Em tempos aonde os recursos para a ciência são cada vez mais escassos em nosso país, os pesquisadores brasileiros demonstram o seu importante papel no enfrentamento e resolução de problemas que afligem a população. Os artigos publicados nessa edição refletem a qualidade dos nossos pesquisadores e demonstram que, apesar dos recursos escassos e ataques sofridos, a ciência no Brasil ainda respira e contribui para o desenvolvimento de nosso país. A pandemia trouxe um estado de reflexão geral, destacando a necessidade de fortalecimento da ciência para enfrentamento de problemas análogos no futuro. Que possamos sair desta situação pessoas melhores, mais preparadas e humanas. Desejamos a todos uma boa leitura! Continuem se protegendo e acreditando na ciência!

\section{Conflito de interesse}

Os autores declaram não haver conflito de interesse.

\section{Contribuição dos autores}

Hallal PC, Barbosa Filho VC e Sasaki JE contribuíram de forma similar para a escrita da versão inicial, revisão e aprovação da versão final do editorial.

Recebido: 03/07/2020 Aprovado: 01/12/2020

\section{Como citar este artigo:}

Hallal PC, Barbosa Filho VC, Sasaki JE. A Ciência em reposta à pandemia de COVID-19: contribuições da Revista Brasileira de Atividade Física E' Saúde. Rev Bras Ativ Fís Saúde. 2020;25:e0138.. DOI: 10.12820/rbafs.25e0138 